\title{
Neutropenic Enterocolitis as Possible Complication of Docetaxel and Epirubicin Chemotherapy for Breast Cancer: Report of 3 Cases
}

\author{
Davide Lombardi*, Venturini S and Veronesi A \\ Divisions of Medical Oncology C and Radiology, National Cancer Institute, Aviano, Italy
}

\section{Case Report}

Neutropenic enterocolitis (typhilitis) is a rare complication of chemotherapy-related neutropenia in cancer patients (Cunningham et al., 2005; Davila, 2006; Hsu et al., 2006; D’Amato et al., 2006; Ibrahim et al., 2000). Its main clinico-pathologic features include segmental ulceration of the caecum and ascending colon which may progress to necrosis and peritonitis. Its pathogenesis appears to result from a combination of mucosal damage and impaired host defences to intestinal microorganisms (Cunningham et al., 2005; D'Amato et al., 2006).

We report on 3 homogeneously treated patients presenting neutropenic enterocolitis following Docetaxel and Epirubicin chemotherapy for advanced breast cancer. In all 3 cases doses were $75 \mathrm{mg} / \mathrm{m}^{2}$ for Docetaxel and $90 \mathrm{mg} / \mathrm{m}^{2}$ for Epirubicin plus prednisone medication. Treatment was repeated every 3 weeks.

\section{Case \#1}

A 38-year-old woman was admitted with G4 neutropenia, crampy abdominal pain, nausea and vomiting in June 2004 on day 7 of cycle 1. An abdominal film showed non-specific colon distension and wall thickening. Emergency laparotomy and right hemicolectomy were performed. Histology showed multiple caecal and colonic ulcerations and chronic and acute inflammation. The patient had a long stay at the Intensive Care Unit due to myasthenia and eventually recovered. She died due to disease in December 2009.

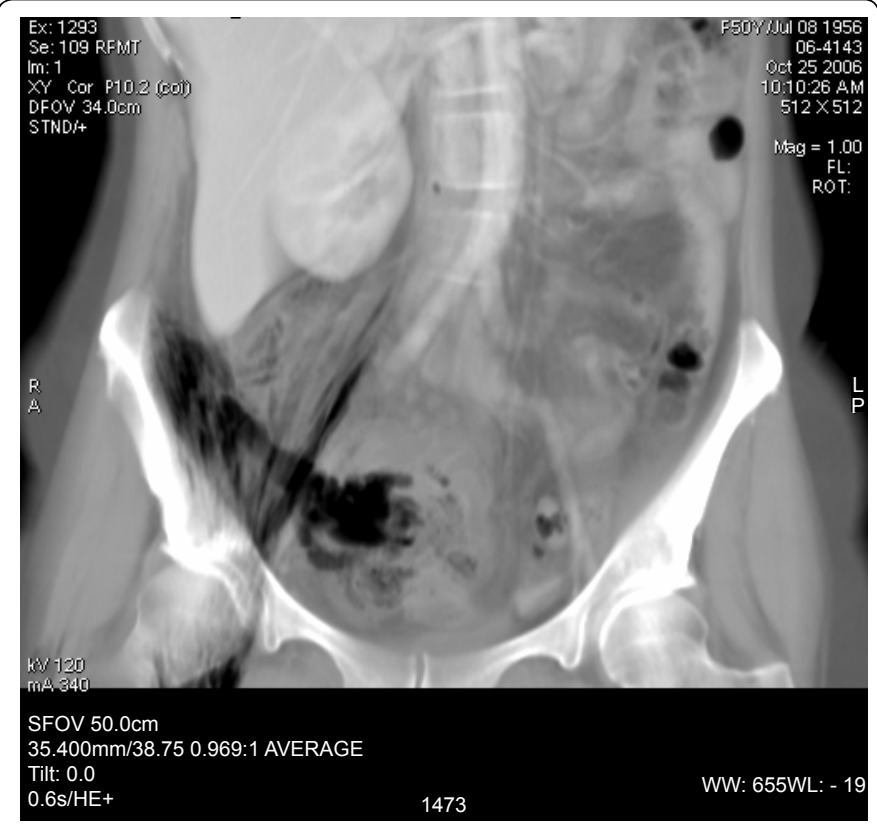

Figure 1: Case \#3: Reformatted coronal reconstruction of raw axial CT scan showing massive retro-pneumoperitoneum with gangrenous gas extending along the right ileo-psoas muscle path to the right inguinal region.

\section{Case \#2}

A 46-year-old woman was admitted in another Hospital with neutropenic fever, crampy abdominal pain and vomiting.in December 2005 on day 10 of cycle 1 . Subsequently she was transferred to the Intensive Care Unit at our Centre for hypotension and septic shock. Abdomen CT showed inflammation and swelling of right bowel. Emergency laparotomy and right hemicolectomy were performed. The patient died shortly after surgery.

\section{Case \#3}

A 50-year-old woman was admitted with fever, crampy abdominal pain, G3 neutropenia, nausea and vomiting in October 2006 on day 12 of cycle 2. Abdomen CT (Figure 1) showed peritonitis, adhesion of ileocaecal loops and caecal perforation with pneumoperitoneum. Exploratory laparotomy and right hemicolectomy and oophorectomy were performed. Histology showed full thickness necrosis associated with acute and chronic inflammation. The patient had a long stay at the Intensive Care Unit due to septic shock, complicated by Clostridium Septicum leg myonecrosis (gas gangrene) treated with hyperbaric oxygen. She is presently well.

Neutropenic enterocolitis occurred at least 3 times in a population of approximately 150 pts treated with Docetaxel and Epirubicin over a 5 year period. No other case occurred at our Institution in breast cancer patients in that period. This complication should be considered in the event of rapid onset abdominal pain in a Docetaxel and Epirubicin treated patient. Worth of note, syptoms in our patients were rather aspecific at onset, with no overt sign of peritonitis. In neutropenic patients, attention should be paid even to vague abdominal discomfort. Urgent CT scan evaluation and early surgery appear to be of great importance.

\section{References}

1. Cunningham SC, Fakhry K, Bass BL, Napolitano LM (2005) Neutropenic enterocolitis in adults: case series and review of the literature. Dig Dis Sci 50 215-220.

*Corresponding author: Davide Lombardi MD, Divisions of Medical Oncology $C$ and Radiology, National Cancer Institute, Aviano, Italy, Tel: +39 0434 659028; Fax: +39 0434 659453; E-mail: dlombardi@cro.it

Received September 06, 2010; Accepted October 23, 2010; Published Octobe 23, 2010

Citation: Lombardi D, Venturini S, Veronesi A (2011) Neutropenic Enterocolitis as Possible Complication of Docetaxel and Epirubicin Chemotherapy for Breas Cancer: Report of 3 Cases. J Cancer Sci Ther 3: 005-006. doi:10.4172/19485956.1000048

Copyright: (c) 2011 Lombardi D, et al. This is an open-access article distributed under the terms of the Creative Commons Attribution License, which permits unrestricted use, distribution, and reproduction in any medium, provided the original author and source are credited. 
Citation: Lombardi D, Venturini S, Veronesi A (2011) Neutropenic Enterocolitis as Possible Complication of Docetaxel and Epirubicin Chemotherapy for Breast Cancer: Report of 3 Cases. J Cancer Sci Ther 3: 005-006. doi:10.4172/1948-5956.1000048

2. Davila ML (2006) Neutropenic enterocolitis. Curr Opin Gastroenterol 22: 44-47.

3. Hsu SD, Chou SJ, Hsieh HF, Yu JC (2006) A case of breast carcinoma, chemotherapy and acute appendicitis. Lancet 368: 1038

4. D'Amato G, Rocha Lima C, Mahany JJ, Muro-Cacho C, Haura EB (2004) Neutropenic enterocolitis (typhilitis) associated with docetaxel therapy in a patient with non-small-cell lung cancer: a case report and review of literature. Lung Cancer 44: 381-390.

5. Ibrahim NK, Sahin AA, Dubrow RA, Lynch PM, Boehnke-Michaud L, et al (2000) Colitis associated with docetaxel-based chemotherapy in patients with metastatic breast cancer. Lancet 355: 281-283. 